\title{
Plasma sFlt-1 Fluctuations in Response to Pulmonary Arterial Hypertension Treatment
}

\author{
Bouzina $\mathrm{H}^{1,2 *}$, Nielsen $\mathrm{S}^{3,4}$, Scheele $\mathbf{C}^{3-5}$ and Rådegran $\mathbf{G}^{1,2}$ \\ ${ }^{1}$ Department of Clinical Sciences Lund, Cardiology, Lund University, Lund, Sweden \\ ${ }^{2}$ The Hemodynamic Lab. The Section for Heart Failure and Valvular Disease, VO Heart and Lung Medicine, Skåne University Hospital, Lund, Sweden \\ ${ }^{3}$ The Centre for Inflammation and Metabolism, University of Copenhagen and Rigshospitalet, Copenhagen, Denmark \\ ${ }^{4}$ Centre for Physical Activity Research, University of Copenhagen and Rigshospitalet, Copenhagen, Denmark \\ ${ }^{5}$ The Novo Nordisk Foundation Center for Basic Metabolic Research, University of Copenhagen, Denmark
}

\begin{abstract}
Background: Pulmonary Arterial Hypertension (PAH) is characterized by vasoconstriction and remodeling of distal pulmonary arteries, which result in increased Pulmonary Vascular Resistance (PVR) and right ventricular overload. In the present study, we measured plasma fluctuations of nine proteins, involved in inflammation or tyrosine kinase signaling, in PAH patients, to assess their value as biomarkers of treatment response.

Methods: Plasma vascular endothelial growth factor $A$ and D, soluble fms-like tyrosine kinase-1 (sFlt-1), placenta growth factor, fibroblast growth factor 2, angiopoietin-1 receptor, interleukin (IL)-6 and -8 and tumor necrosis factor a were determined by multiplex immunoassays in 21 treatment-naïve PAH patients at baseline and at first and second clinical checkups.

Results: From baseline to first checkup, sFIt-1 $(p<0.02)$ and IL-6 $(p<0.005)$ decreased in PAH patients. sFIt-1 remained decreased $(p<0.003)$ at the second checkup, compared to baseline. No significant changes were observed in the other measured biomarkers. Patients receiving initial combination therapy showed a more marked initial decrease $(p<0.02)$ in plasma sFIt-1, compared to initial monotherapy. Plasma sFIt-1 changes correlated positively with changes in PVR and negatively with changes in left ventricular stroke work index (LVSWI).

Conclusion: Plasma sFlt-1 is significantly reduced after the initiation of PAH-specific treatment and its fluctuations are correlated to changes in PVR and LVSWI. Thus, plasma sFIt-1 is a new potential biomarker for evaluating treatment response in $\mathrm{PAH}$.
\end{abstract}

Keywords: Biomarkers; Pulmonary arterial hypertension; sFlt-1; Treatment response

\section{Introduction}

Pulmonary Arterial Hypertension (PAH) patients suffer from dyspnea, right ventricular failure and a marked decline in life quality, due to severe vasoconstriction and remodeling of small pulmonary arteries. Defect endothelin, prostacyclin and nitric oxide vasoregulatory pathways are key pathological processes that are addressed by current $\mathrm{PAH}$-specific drugs. Until recently, de novo $\mathrm{PAH}$ patients, in WHO-functional class (WHO-FC) II-IV, have been recommended to receive initial monotherapy, followed by a sequential combination approach, when treatment response was inadequate [1]. However, new guidelines from the European Society of Cardiology and the European Respiratory Society additionally include recommendations for initial combination therapy [2]. Such approach targets multiple defect vasoregulatory pathways at PAH diagnosis, which may result in a more efficacious treatment response.

Besides more efficient treatment approaches, novel biomarkers would be of value to improve clinical management in PAH. Ideal biomarkers could be important components in earlier PAH detection, monitoring disease progression, risk assessment or pulmonary hypertension subgroup differentiation. Biomarkers could also be used to evaluate treatment response or hemodynamic impairment, the latter being especially valuable in smaller PAH centers that cannot perform regular hemodynamic evaluations.

Pulmonary arteries in PAH manifest with intimal thickening and fibrosis, medial hypertrophy, adventitial reconstruction and formation of complex lesions [3]. Altered circulating biomarkers in PAH, such as interleukin (IL)-6 and tumor necrosis factor $\alpha$ (TNF- $\alpha$ ) [4], could reflect crucial cascades that influence vascular remodeling. For instance, IL-6 is suggested to depress bone morphogenetic protein receptor type II (BMPR2) [5]. Its overexpression in mice results in pulmonary vascular and cardiac remodeling similar to that observed in PAH patients [6] Receptor Tyrosine Kinases (RTK) and their ligands also constitute an intriguing molecular domain, which could have a major involvement in vascular remodeling. For instance, fibroblast growth factor 2 (FGF-2), whose blood-borne levels are elevated in PAH [7], is linked to smooth muscle cell growth [8]. In contrast, inhibiting Vascular Endothelial Growth Factor (VEGF)-A, through the suppression of VEGF receptor (VEGFR)-1 and -2, using the tyrosine kinase inhibitor Sugen, results in severe PAH in rats that are exposed to chronic hypoxia [9]. VEGF-A overexpression is furthermore suggested to be protective in $\mathrm{PAH}$ animal models $[10,11]$, although its human circulating concentrations are elevated $[12,13]$. Moreover, the soluble fms-like tyrosine kinase-1 (sFlt-1, also known as soluble VEGFR1), which blunts VEGF-A signaling [14], is also increased in blood samples from PAH patients $[15,16]$, and could therefore resemble a role similar to that of Sugen.

*Corresponding author: Habib Bouzina, The Hemodynamic Lab, The Section for Heart Failure and Valvular Disease, VO Heart and Lung Medicine, Skåne University Hospital, Lund, Sweden, Tel: +46 737472 914; E-mail: habib.bouzina@med.lu.se

Received March 18, 2017; Accepted April 10, 2017; Published April 17, 2017

Citation: Bouzina H, Nielsen S, Scheele C, Rådegran G (2017) Plasma sFlt1 Fluctuations in Response to Pulmonary Arterial Hypertension Treatment. Cardiovasc Pharm Open Access 6: 207. doi: 10.4172/2329-6607.1000207

Copyright: (c) 2017 Bouzina H, et al. This is an open-access article distributed under the terms of the Creative Commons Attribution License, which permits unrestricted use, distribution, and reproduction in any medium, provided the original author and source are credited. 
To identify new potential biomarkers for treatment response evaluation in $\mathrm{PAH}$, we investigated nine proteins involved in inflammatory cascades or tyrosine kinase signaling. We hypothesized that hemodynamic attenuation after treatment debut could result in a normalization of such biomarker concentrations, and that these levels may be more potently affected by initial combination than initial monotherapy.

\section{Materials and Methods}

\section{Inclusion and exclusion criteria}

Patients ( $\geq 18$ years) who received a PAH diagnosis between 01 September 2011 and 01 April 2015 and were followed with two early consecutive Right Heart Catheterization (RHC) checkups, at the Hemodynamic lab at Skåne University Hospital in Lund, Sweden, were included. The study population included 12 Idiopathic PAH (IPAH), 1 hereditary PAH (HPAH), 1 rheumatoid arteritis PAH and 7 systemic sclerosis-associated PAH (SSc-PAH) patients, who had received either initial combination $(n=5)$ or initial monotherapy $(n=16)$.

IPAH and HPAH were treated as one entity $(n=13)$. Connective tissue disease-associated PAH (CTD-PAH) patients were regarded as another entity $(n=8)$. The study was approved by the local ethics board in Lund (Dnr 2015/270, Dnr 2011/777, Dnr 2011/368, Dnr 2010/114, and Dnr 2010/442).

\section{Plasma sampling and biomarker analyses}

VEGF-A, VEGF-D, sFlt-1, Placenta Growth Factor (PlGF), FGF-2, angiopoietin- 1 receptor (Tie-2), IL-6, IL-8 and TNF- $\alpha$ were analyzed by multiplex sandwich immunoassays (Meso Scale Discovery, Rockville, MD, USA), in plasma derived from blood samples collected from pulmonary arteries during the RHC procedures. Plasma was collected after centrifugation and stored at $-80^{\circ} \mathrm{C}$ in the Lund Cardio Pulmonary Register (LCPR) cohort of Region Skånes bio bank, established by Dr. Göran Rådegran in September 2011.

\section{Hemodynamic assessments and calculations}

RHCs were performed using Swan-Ganz catheters. Cardiac Output (CO) was measured using thermo dilution. Body Surface Area (BSA), Heart Rate (HR), Mean Right Atrial Pressure (MRAP), Mean Arterial Pressure (MAP), Mean Pulmonary Artery Pressure (MPAP), Pulmonary Artery Wedge Pressure (PAWP) and CO were gathered in order to calculate Stroke Volume (SV), left ventricular stroke work index (LVSWI), right ventricular stroke work index (RVSWI), Systemic Vascular Resistance (SVR) and Pulmonary Vascular Resistance (PVR). The formulae used were: $\mathrm{SV}=\mathrm{CO} / \mathrm{HR}, \mathrm{PVR}=\mathrm{MPAP}-\mathrm{PAWP} /$ $\mathrm{CO}, \mathrm{SVR}=(\mathrm{MAP}-\mathrm{MRAP}) / \mathrm{CO}, \mathrm{LVSWI}=(\mathrm{MAP}-\mathrm{PAWP}) \times \mathrm{SV} / \mathrm{BSA}$ and RVSWI $=($ MPAP-MRAP $) \times$ SV/BSA .

\section{Study design}

Hemodynamics, N-terminal prohormone of brain natriuretic peptide (NT-proBNP), 6-minute walking distance (6MWD) and WHO-FC were retrieved from medical records.

The parameters were compared between the three observational time points, e.g. baseline as well as first and second checkups, in all PAH patients. Correlations between biomarker fluctuations and changes in MPAP, PAWP, MRAP, CO, PVR, SVR, RVSWI, LVSWI, 6MWD and NT-proBNP were additionally evaluated in all patients.

The study population was divided into initial combination and monotherapy groups. The parameters were also compared between the three observational time points for the initial combination and monotherapy groups separately. Changes in the parameters, referred to as treatment responses, were measured between baseline and respective checkup, and were compared between initial combination and monotherapy groups. Baseline values were also compared between these two groups. Similar analyses were additionally implemented for the study population divided into IPAH/HPAH and CTD-PAH groups.

\section{Statistics}

The Friedman test was used to compare the three observation time points within a group. Dunn's test with adjusted p-values was used for multiple comparison analyses, where first and second checkup measurements were tested against the baseline measurement. The Mann Whitney U-test was used to compare baseline characteristics as well as treatment responses between two groups. Spearman's correlation tests were used for the correlation studies. All results are presented as median (interquartile range). $\mathrm{P}<0.05$ was considered statistically significant. Friedman, Dunn's and Spearman's tests were conducted using GraphPad Prism (Version 6, GraphPad Software, La Jolla, California, USA), and the other analyses were conducted using $\mathrm{R}$ software (R Foundation for Statistical Computing, Vienna, Austria).

\section{Results}

\section{Study population characteristics}

Baseline characteristics for all patients pooled and divided into initial combination and monotherapy groups, or IPAH/HPAH and CTD-PAH groups, are presented in Table 1. The initial combination therapy group exhibited a higher $\operatorname{PVR}(\mathrm{p}<0.005)$, as well as a lower CO $(\mathrm{p}<0.03)$ and LVSWI $(\mathrm{p}<0.006)$, compared to the initial monotherapy group.

The initial combination therapy group consisted of 2 IPAH, 1 $\mathrm{HPAH}$ and $2 \mathrm{SSc}-\mathrm{PAH}$ patients. In the initial monotherapy group, there were $10 \mathrm{IPAH}, 5 \mathrm{SSc}-\mathrm{PAH}$ and 1 rheumatoid arteritis $\mathrm{PAH}$ patients. Due to missing values, 2 IPAH and 1 CTD-PAH patients receiving either initial combination therapy $(n=1)$ or monotherapy $(n=2)$, were excluded from the 6MWD analyses. For all NT-proBNP analyses, 4 IPAH and 2 CTD-PAH patients, receiving initial combination $(n=1)$ or monotherapy $(\mathrm{n}=5)$, were also excluded due to missing values.

\section{Medical regimens in the study population}

Patients in the initial monotherapy group $(n=16)$ received bosentan $(\mathrm{n}=8)$, ambrisentan $(\mathrm{n}=2)$, sildenafil $(\mathrm{n}=3)$, tadalafil $(\mathrm{n}=1)$ or the calcium channel blocker nifedipin $(n=2)$. Of those with PAH-specific drugs, one patient had also received nifedipin for rheumatologic symptoms during the entire observation time, one until first checkup and one only before diagnosis.

9 of 16 patients were escalated to a combination of PAH-specific drugs already at the first checkup, and received bosentan and sildenafil $(n=6)$, bosentan and tadalafil $(n=1)$, ambrisentan and sildenafil $(n=1)$ or ambrisentan and tadalafil $(\mathrm{n}=1)$. At first checkup, the remaining patients continued on nifedipin $(n=1)$, sildenafil $(n=1)$ or bosentan $(n=3)$, or were changed to macitentan $(n=1)$ or nifedipin and sildenafil $(\mathrm{n}=1)$.

Patients in the initial combination group $(n=5)$ received ambrisentan and tadalafil $(n=3)$, bosentan and sildenafil $(n=1)$ or macitentan, tadalafil and treprostinil $(n=1)$. One of the patients received nifedipin for rheumatologic symptoms during the entire observation time. At first checkup, all these patients continued the same drug combinations. 
Citation: Bouzina H, Nielsen S, Scheele C, Rådegran G (2017) Plasma sFlt-1 Fluctuations in Response to Pulmonary Arterial Hypertension Treatment. Cardiovasc Pharm Open Access 6: 207. doi: 10.4172/2329-6607.1000207

Page 3 of 9

\begin{tabular}{|c|c|c|c|c|c|}
\hline & All patients & CTD-PAH & IPAH/HPAH & $\begin{array}{l}\text { Initial combination } \\
\text { therapy }\end{array}$ & Initial monotherapy \\
\hline Sample size (\% females) & $21(71)$ & $8(100)$ & $13(54)$ & $5(80)$ & $16(69)$ \\
\hline Age (years) & $70(57-75)$ & $70(62-73)$ & $72(57-75)$ & $55(45-70)$ & $72(66-77)$ \\
\hline $\mathrm{BSA}\left(\mathrm{m}^{2}\right)$ & $1.78(1.7-2.08)$ & $1.72(1.69-1.77)$ & $1.89(1.77-2.17)$ & $1.78(1.66-2.08)$ & $1.78(1.7-2.05)$ \\
\hline WHO-FC & $3(3-3)$ & $3(3-3)$ & $3(3-3)$ & $3(3-3)$ & $3(3-3)$ \\
\hline 6MWD (m) & $213.5(142.5-258.5)$ & $207(157.5-251)$ & $220(162.5-260)$ & $241.5(213.8-278.5)$ & $203.5(121.3-243.5)$ \\
\hline NT-proBNP (ng/l) & 2359 (1666.5-3088.5) & 3259.5 (2603.8-4089.3) & 1689 (843-2359)† & $2634.5(2338.8-2977.8)$ & 2325 (1243.5-3088.5) \\
\hline \multicolumn{6}{|c|}{ Hemodynamics } \\
\hline MPAP $(\mathrm{mmHg})$ & $45(39-55)$ & $41.5(38.8-44.3)$ & $50(42-55)$ & $56(50-57)$ & $43.5(38.8-49.8)$ \\
\hline PAWP (mmHg) & $6(5-7)$ & $6(5-6.3)$ & $6(5-7)$ & $6(6-7)$ & $6(5-6.3)$ \\
\hline MRAP $(\mathrm{mmHg})$ & $7(6-9)$ & $7(6-10)$ & $7(4-9)$ & $9(7-11)$ & $6(4-8.3)$ \\
\hline $\mathrm{CO}\left(1 \cdot \mathrm{min}^{-1}\right)$ & $3.6(3-4.6)$ & $3.6(3.1-4.7)$ & $3.6(3-4.4)$ & $3(2.9-3)$ & $3.9(3.4-4.9)^{*}$ \\
\hline PVR (WU) & $10.2(7.9-12.4)$ & $8.9(7.2-11)$ & $11.9(8.2-14.5)$ & $16.9(14.9-17.2)$ & $8.8(7.3-11.3)^{*}$ \\
\hline SVR (WU) & $25.4(18.3-28.3)$ & $23.1(17.7-25.9)$ & $26(19.8-32.4)$ & $26.7(26-32.4)$ & $23.6(17.2-27.1)$ \\
\hline $\mathrm{RVSWI}\left(\mathrm{mmHg} \cdot \mathrm{ml} \cdot \mathrm{m}^{-2}\right)$ & $921.7(800.6-1137.7)$ & $853.9(799.2-975.7)$ & $1001.6(800.6-1211.2)$ & 800.6 (776.8-898.9) & $1005.9(808.4-1230.5)$ \\
\hline LVSWI $\left(\mathrm{mmHg} \cdot \mathrm{ml} \cdot \mathrm{m}^{-2}\right)$ & $2159.4(1969.7-2600.7)$ & $2133.1(1919.7-2755)$ & $2175.7(1969.7-2600.7)$ & $1635.3(1598.5-1863)$ & $2429.3(2114-2938.8)^{*}$ \\
\hline \multicolumn{6}{|c|}{ Biomarkers } \\
\hline FGF-2 (pg/ml) & $15.16(10.75-20.64)$ & $14.02(9.99-14.43)$ & $17.89(13.49-26.11)$ & $17.47(14.18-18.65)$ & $14.66(10.1-23.48)$ \\
\hline PIGF (pg/ml) & $31.02(21.74-38.14)$ & $39.22(30.93-44.85)$ & $30.44(21.07-32.68)$ & $30.66(18.09-32.68)$ & $31.45(26.86-39.58)$ \\
\hline $\mathrm{sFlt}-1$ (pg/ml) & $124(95.2-148.9)$ & $125.9(92-330.5)$ & $124(103.6-144.2)$ & $188(130.6-214.1)$ & $119.3(89.2-138.7)$ \\
\hline Tie-2 (pg/ml) & $3284.8(2818.9-3607.4)$ & $2832.5(2741.4-3168.7)$ & 3415.9 (2984-3769.6) & $3284.8(3110.3-3415.9)$ & $3163.9(2813.1-3695.7)$ \\
\hline VEGF-A (pg/ml) & $81(73.6-150.4)$ & $133.9(79.8-222.5)$ & $74.4(62.5-131.2)$ & $74.3(73.6-79.9)$ & $122.7(72.7-155.1)$ \\
\hline VEGF-D (pg/ml) & $1222.8(801.5-1322.7)$ & $1351.7(1224.8-1482)$ & $905.8(712.5-1230.5) \dagger$ & $1222.8(690.3-1232.4)$ & $1216.3(853.2-1357.8)$ \\
\hline IL-6 (pg/ml) & $1.58(0.9-3.8)$ & $2.3(1.42-3.67)$ & $1.37(0.86-3.8)$ & $1.47(0.9-1.85)$ & $1.69(1-3.84)$ \\
\hline IL-8 (pg/ml) & $5.35(3.84-7.96)$ & $8.48(6.54-9.62)$ & $4.6(3.74-6.34) \dagger$ & $6.34(4.6-6.94)$ & $5.24(3.73-8.22)$ \\
\hline TNF- $\alpha(p g / m l)$ & $3.39(2.79-4.28)$ & $4.12(3.37-4.72)$ & $3.21(2.55-3.6)$ & $2.55(2.47-3.39)$ & $3.5(3.2-4.33)$ \\
\hline
\end{tabular}

Continuous variables are presented as median (interquartile range). Values significantly different between initial combination versus monotherapy groups are marked by a ${ }^{*}$. Baseline values significantly different between CTD-PAH versus IPAH/HPAH are marked by a †. Age, BSA and WHO-FC are used for descriptive purposes. 6MWD: 6 Minute Walk Distance; BSA: Body Surface Area; CO: Cardiac Output; CTD-PAH: Connective Tissue Disease Pulmonary Arterial Hypertension; HPAH: Hereditary Pulmonary Arterial Hypertension; IPAH: Idiopathic Pulmonary Arterial Hypertension; MPAP: Mean Pulmonary Arterial Pressure; MRAP: Mean Right Atrial Pressure; NT-proBNP: N-Terminal Prohormone of Brain Natriuretic Peptide; PAWP: Pulmonary Artery Wedge Pressure; PVR: Pulmonary Vascular Resistance; RVSWI: Right Ventricular Stroke Work Index; SVR: Systemic Vascular Resistance; WHO-FC: World Health Organization Functional Class; WU: Wood Unit; FGF-2: Fibroblast Growth Factor 2; IL: Interleukin; PIGF: Placental Growth Factor; sFIt-1: Soluble Fms-Like Tyrosine Kinase-1; Tie-2: Angiopoetic 1 Receptor; TNF-a: Tumor Necrosis Factor a; VEGF: Vascular Endothelial Growth Factor.

Table 1: Baseline characteristics of the study population.

Fluctuations of plasma biomarker levels, hemodynamics, NTproBNP and 6MWD

The time from baseline to the first and second checkups were 112 (92-117) and 264 (183-327) days, respectively.

From diagnosis to the first checkup, CO increased $(\mathrm{p}<0.0004)$ while IL-6 $(\mathrm{p}<0.005)$, sFlt-1 $(\mathrm{p}<0.02)$, PVR $(\mathrm{p}<0.0005)$, SVR $(\mathrm{p}<0.0002)$ and NT-proBNP $(\mathrm{p}<0.03)$ decreased in all PAH patients pooled (Figures 1-3). From diagnosis to the second checkup, 6MWD ( $<<0.02), C O$ $(\mathrm{p}<0.007)$ and LVSWI $(\mathrm{p}<0.05)$ increased while sFlt-1 $(\mathrm{p}<0.003)$, MPAP $(\mathrm{p}<0.005)$, PVR $(\mathrm{p}<0.0001)$, SVR $(\mathrm{p}<0.0003)$ and NT-proBNP $(\mathrm{p}<0.03)$ decreased (Figures 1-3).

From diagnosis to the first checkup, SVR was decreased in both the initial combination $(\mathrm{p}<0.03)$ and monotherapy $(\mathrm{p}<0.003)$ groups (Figure 1). CO increased $(\mathrm{p}<0.005)$ and IL-6 $(\mathrm{p}<0.006)$ as well as PVR $(\mathrm{p}<0.006)$ decreased only in the initial monotherapy group (Figures 1 and 3). sFlt-1 decreased $(\mathrm{p}<0.03)$ only in the initial combination therapy group (Figure 3). During this period, the treatment effects on sFlt-1 $(\mathrm{p}<0.02)$, PVR $(\mathrm{p}<0.002)$ and SVR $(\mathrm{p}<0.02)$ were more powerful in the initial combination group compared to the initial monotherapy group.

From diagnosis to the second checkup, PVR decreased in both the initial combination $(\mathrm{p}<0.03)$ and monotherapy $(\mathrm{p}<0.0003)$ groups (Figure 1). sFlt-1 $(\mathrm{p}<0.03), \operatorname{MPAP}(\mathrm{p}<0.05)$ and SVR $(\mathrm{p}<0.003)$ decreased only in the initial monotherapy group (Figure 1). CO $(\mathrm{p}<0.03)$ and TNF- $\alpha(\mathrm{p}<0.03)$ increased only in the initial combination therapy group (Figures 1 and 3 ). During this period, the treatment effects on PVR $(\mathrm{p}<0.05)$ and LVSWI $(\mathrm{p}<0.05)$ were more powerful in the initial combination group compared to the initial monotherapy group. Treatment responses for TNF- $\alpha$ were different $(p<0.05)$ between the initial combination versus monotherapy group.

Results for the population divided into IPAH/HPAH and CTD$\mathrm{PAH}$ are presented in Table 1 and Figure 4. From diagnosis to the first checkup, sFlt-1 decreased for the CTD-PAH patients $(p<0.02)$ (Figure 4). From diagnosis to the second checkup, sFlt-1 decreased 
A

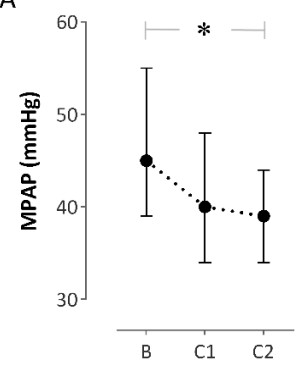

C

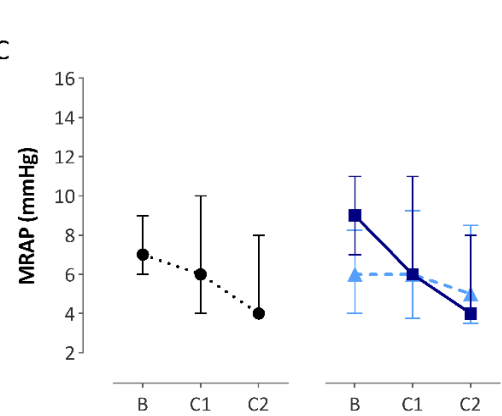

E

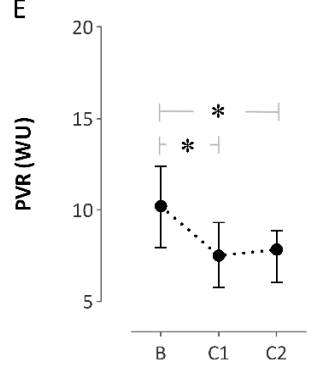

G

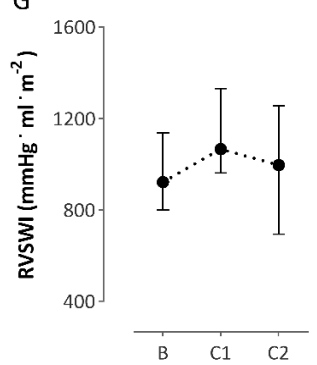

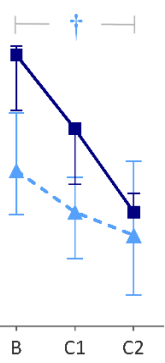
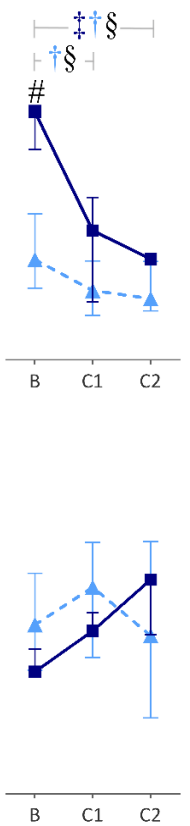

B

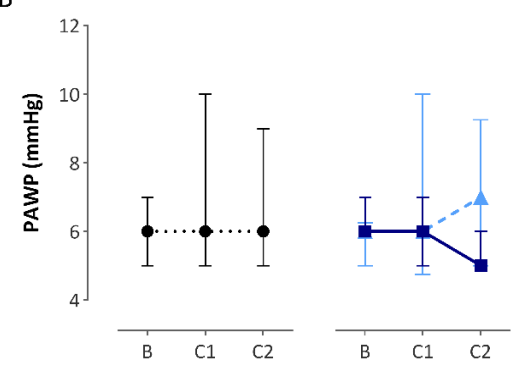

D

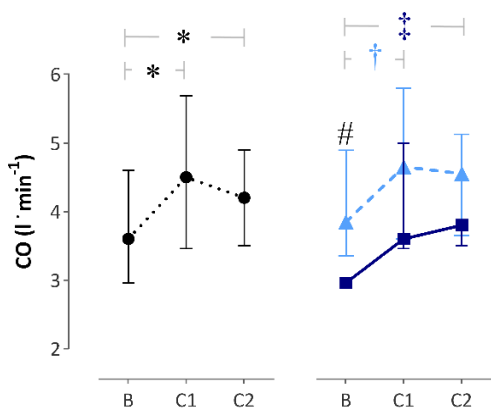

F

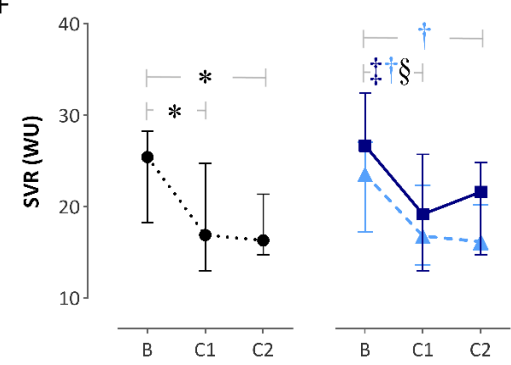

H

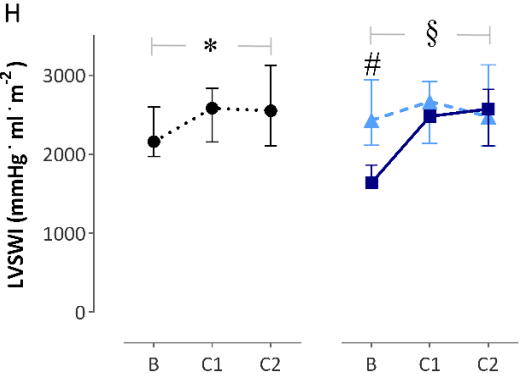

Patients are pooled $(\cdots \bullet \cdots)$, or divided into initial combination $(--)$ ) and monotherapy $\left(\cdots{ }^{--}\right)$groups. * indicates a significant change in the pooled group, during the marked period. $\ddagger$ indicates a significant change in the initial combination therapy group. $\dagger$ indicates a significant change in the initial monotherapy group. $\S$ indicates that the changes between the initial combination and monotherapy groups are significantly different. \# marks significantly different baseline values between the initial combination and monotherapy groups. B: Baseline; C1: First Checkup; C2: Second Checkup; CO: Cardiac Output; LVSWI: Left Ventricular Stroke Work Index; MPAP: Mean Pulmonary Arterial Pressure; MRAP: Mean Right Atrial Pressure; PAWP: Pulmonary Artery Wedge Pressure; PVR: Pulmonary Vascular Resistance; RVSWI: Right Ventricular Stroke Work Index; SVR: Systemic Vascular Resistance; WU: Wood Unit.

Figure 1: Changes of hemodynamics in PAH patients, pooled or divided into initial combination or monotherapy groups.

for the IPAH/HPAH group $(\mathrm{p}<0.02)$ (Figure 4$)$. Baseline plasma VEGF-D $(\mathrm{p}<0.02)$, IL-8 $(\mathrm{p}<0.03)$ and NT-proBNP $(\mathrm{p}<0.02)$ levels were increased in the CTD-PAH group compared to IPAH/HPAH (Figure 4). Friedman test indicated a significant difference in PAWP across the three studied observational time points $(\mathrm{p}<0.04)$ in the CTD-PAH group, although Dunn's analyses showed no significant alternations.
MRAP in the IPAH/HPAH group was different between baseline and second checkup $(\mathrm{p}<0.04)$ according to Dunn's test, although the Friedman test was not significant.

Detailed values for hemodynamics, plasma biomarkers and other variables at baseline and checkups are provided in Supplementary Tables 1A-1C. 
A

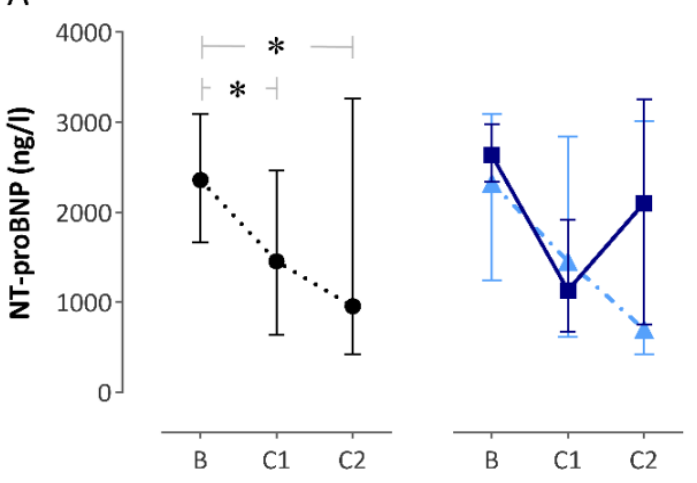

B

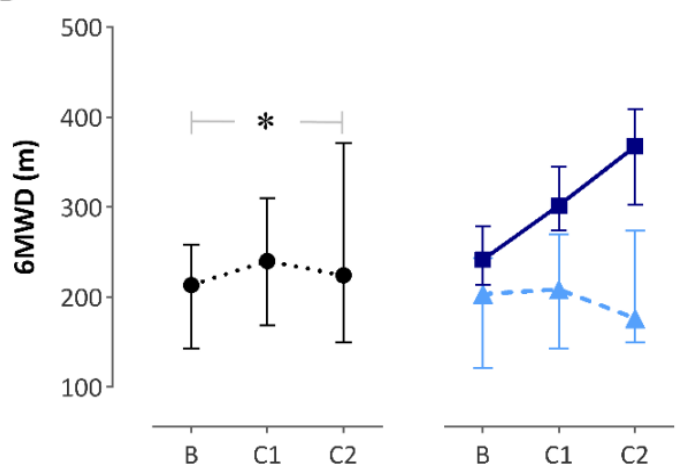

C

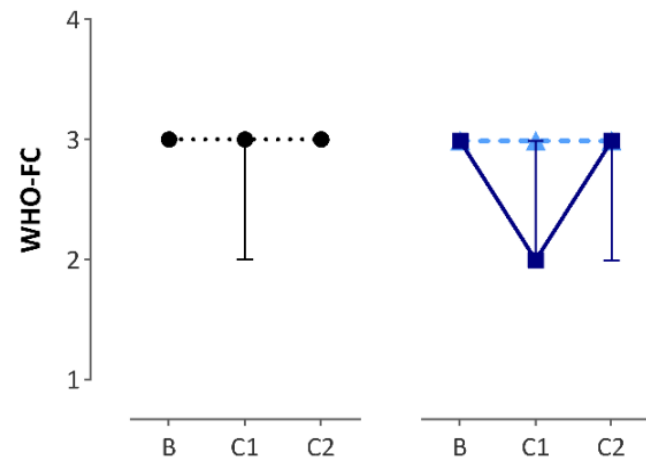

Patients are pooled $(\cdots \bullet \cdot)$, or divided into initial combination $(--)$ ) and monotherapy $\left.(\cdots-)^{--}\right)$groups. * indicates a significant change in the pooled group, during the marked period. WHO-FC is used for descriptive purposes. B: Baseline; C1: First Checkup; C2: Second Checkup; 6MWD: 6-Minute Walk Distance; NT-proBNP: N-Terminal Prohormone of Brain Natriuretic Peptide; WHO-FC: World Health Organization Functional Class.

Figure 2: Changes of NT-proBNP, 6MWD and WHO-FC in PAH patients, pooled or divided into initial combination or monotherapy groups.

\section{Correlations between biomarker fluctuations and changes in other parameters}

Between baseline and the first checkup; sFlt-1 changes correlated with changes in PVR $\left(r_{s}=0.64, p<0.002\right)$, LVSWI $\left(r_{s}=-0.53, p<0.02\right)$ and NT-proBNP $\left(\mathrm{r}_{\mathrm{s}}=0.58, \mathrm{p}<0.03\right)$; and Tie- 2 changes correlated with changes in PVR $\left(\mathrm{r}_{\mathrm{s}}=0.47, \mathrm{p}<0.03\right)$ and NT-proBNP $\left(\mathrm{r}_{\mathrm{s}}=0.64, \mathrm{p}<0.02\right)$ (Figure 5).
Between baseline and second checkup, sFlt- 1 changes correlated with changes of PVR $\left(r_{s}=0.58, p<0.006\right)$, LVSWI $\left(r_{s}=-0.68, p<0.0008\right)$ and $6 \mathrm{MWD}\left(\mathrm{r}_{\mathrm{s}}=-0.67, \mathrm{p}<0.003\right)$; IL- 6 changes correlated to changes in MRAP $\left(r_{s}=0.43, p<0.05\right)$ and RVSWI $\left(r_{s}=-0.49, p<0.03\right)$; IL- 8 changes correlated to changes in $\mathrm{CO}\left(\mathrm{r}_{\mathrm{s}}=-0.45, \mathrm{p}<0.04\right)$; Tie- 2 changes correlated with NT-proBNP changes $\left(r_{s}=0.71, p<0.005\right)$; VEGF-A changes correlated with NT-proBNP changes $\left(\mathrm{r}_{\mathrm{s}}=-0.58, \mathrm{p}<0.03\right)$ and VEGF-D changes correlated with 6MWD $\left(\mathrm{r}_{\mathrm{s}}=0.47, \mathrm{p}<0.05\right)$ and LVSWI $\left(\mathrm{r}_{\mathrm{s}}=0.50\right.$, $\mathrm{p}<0.03$ ) changes (Figure 5).

\section{Discussion}

The present study investigated nine circulating proteins involved in inflammatory cascades or tyrosine kinase signaling to identify new biomarkers for treatment response evaluation in PAH. Our main result demonstrates that PAH treatment decreases plasma sFlt-1, which is a splice variant of the VEGF receptor 1 that inhibits the pro-angiogenic effects of VEGF-A [14]. The sFlt-1 fluctuations furthermore correlated to changes in PVR and LVSWI.

A potential pathogenic role for sFlt-1 in PAH biology is possible although this has, to our knowledge, not been investigated. However, it is intriguing to evaluate previous studies addressing sFlt-1 dysfunction in other vascular abnormalities. Elevated plasma sFlt-1 in chronic kidney disease patients have been shown to positively correlate with plasma levels of soluble vascular cell adhesion molecule-1 (sVCAM-1) and von Willebrand Factor (vWF) [17]. In preeclampsia, which is characterized by hypertension and renal dysfunction, upregulated sFlt-1 has been suggested to contribute to the endothelial dysfunction via depletion of free VEGF-A and PlGF levels [18]. sFlt-1 infusions have furthermore been shown to elevate blood pressure in mice by augmenting endothelin-1-mediated vasoconstriction [19].

Interestingly, sFlt-1-mediated VEGF-A inhibition has previously been proposed to contribute to PAH pathology [20]. This hypothesis is connected to the Sugen chronic hypoxia PAH model, where rats, exposed to chronic hypoxia, were noted to develop severe pulmonary hypertension after inhibition of VEGFR-1 and -2, with the tyrosine kinase inhibitor Sugen (SU5416) [9]. Since circulating sFlt-1 is elevated in PAH $[15,16]$, this protein may constitute a role similar to that of Sugen.

VEGF-A overexpression protects against pulmonary hypertension in monocrotaline and hypoxia animal models $[10,11]$. Also, VEGF-A has been shown to cause vasorelaxation in neonatal piglet pulmonary circulation [21]. In the rat aorta, sFlt-1 has furthermore been shown to inhibit the vasodilatory effects of VEGF-A [22]. Thus, the elevated VEGF-A concentrations observed in blood samples from $\mathrm{PAH}$ patients $[12,13]$, could possibly be a feedback response to increase healthy and capacious vasculature, and consequently decrease vascular pressure. In the current study, the VEGF-A concentrations were, nonetheless, not altered between baseline and either checkup.

Interestingly tough, between baseline and the first checkup in the present study, plasma sFlt-1 was more potently altered in the patients receiving initial combination therapy compared to those receiving initial monotherapy. Recently, the AMBITON trial (ClinicalTrials. gov identifier: NCT01178073) showed that initial combination of ambrisentan and tadalafil was associated with a significantly lower risk of clinical-failure events, compared to initial ambrisentan or tadalafil monotherapy [23]. Kylhammar et al. have furthermore shown that PVR index improved more greatly with initial combination compared to initial monotherapy [24]. In the present study, initial combination therapy showed, compared to initial monotherapy, to have a better effect on some hemodynamic parameters, such as PVR. 
A

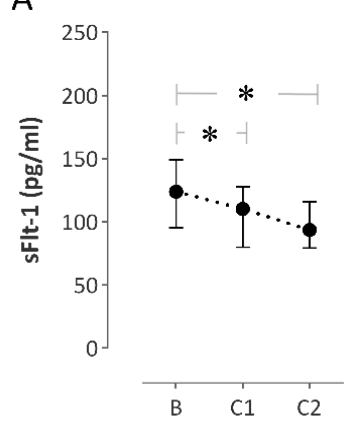

C

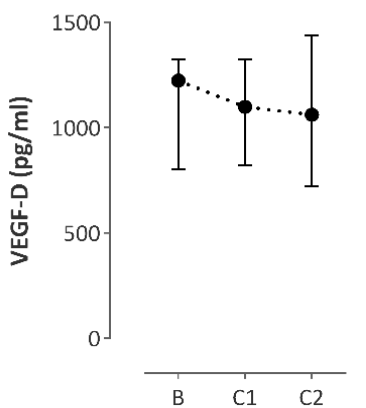

$\mathrm{E}$

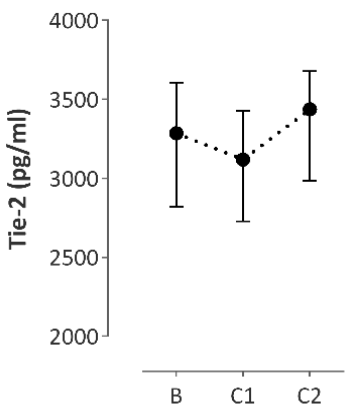

G

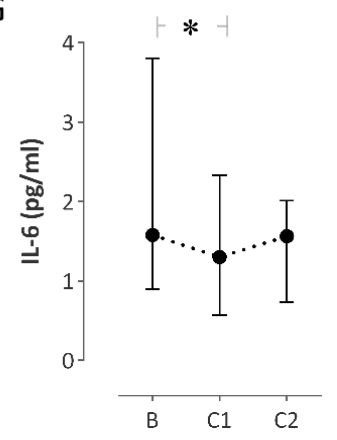

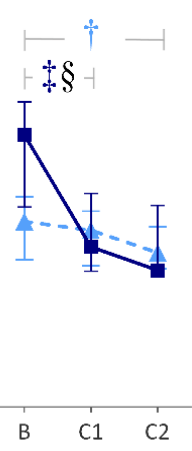
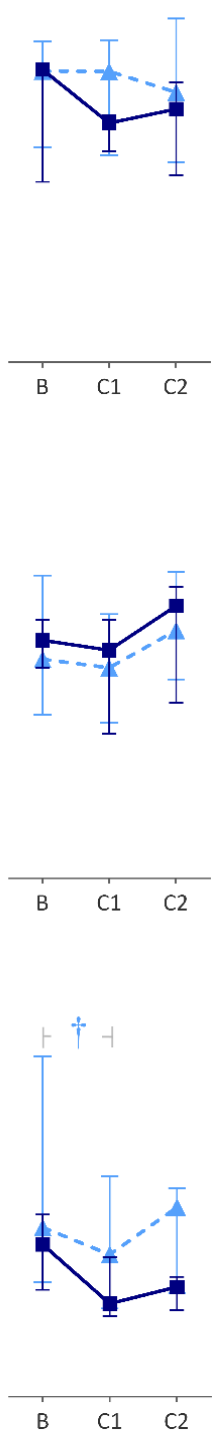

B

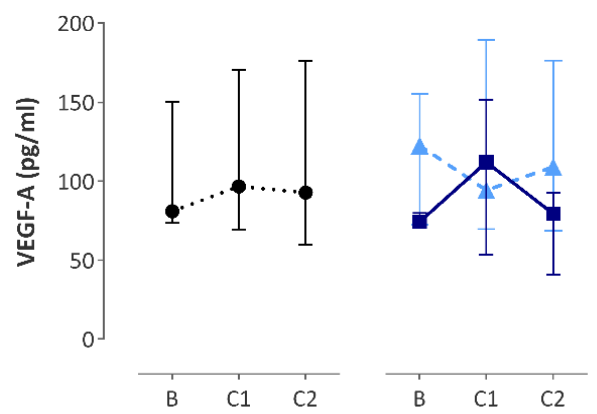

D

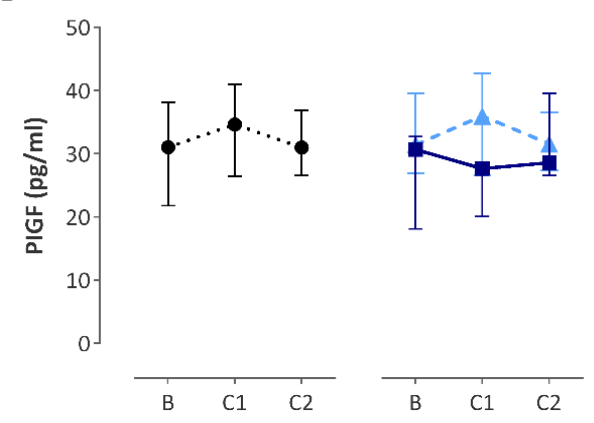

$\mathrm{F}$

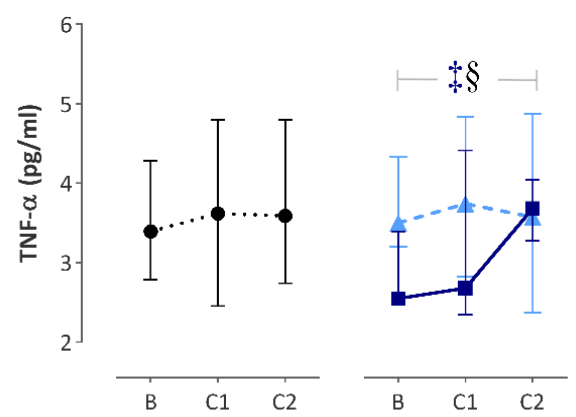

$\mathrm{H}$

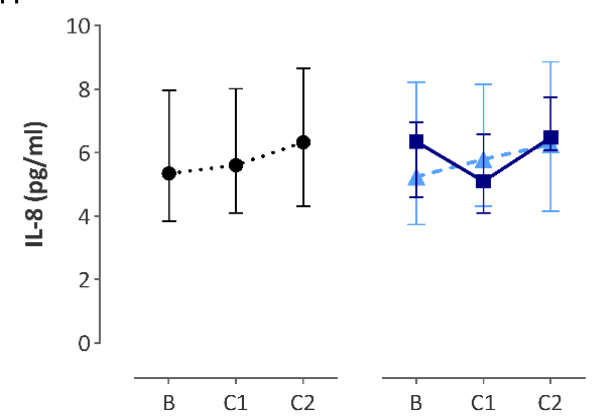

Patients are pooled $(\cdots \bullet \cdots)$, or divided into initial combination $(--)$ ) and monotherapy $\left(\cdots{ }^{--}\right)$groups. * indicates a significant change in the pooled group, during the marked period. $\ddagger$ indicates a significant change in the initial combination therapy group, during the marked period. $\dagger$ indicates a significant change in the initial monotherapy group. § indicates that the changes between the initial combination and monotherapy groups are significantly different. B: Baseline; C1: First Checkup; C2: Second Checkup; FGF-2: Fibroblast Growth Factor 2; IL: Interleukin; PIGF: Placental Growth Factor; sFIt-1: Soluble Fms-Like Tyrosine Kinase-1; Tie-2: Angiopoietin 1 Receptor; TNF- $\alpha$ : Tumor Necrosis Factor $\alpha$; VEGF: Vascular Endothelial Growth Factor.

Figure 3: Changes of selected biomarkers in PAH patients, pooled or divided into initial combination or monotherapy groups. 

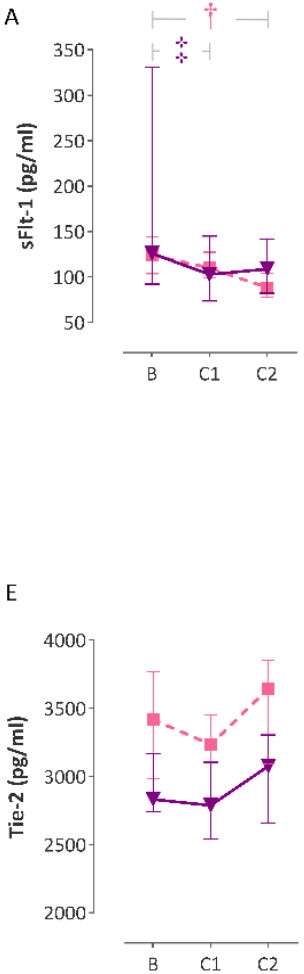
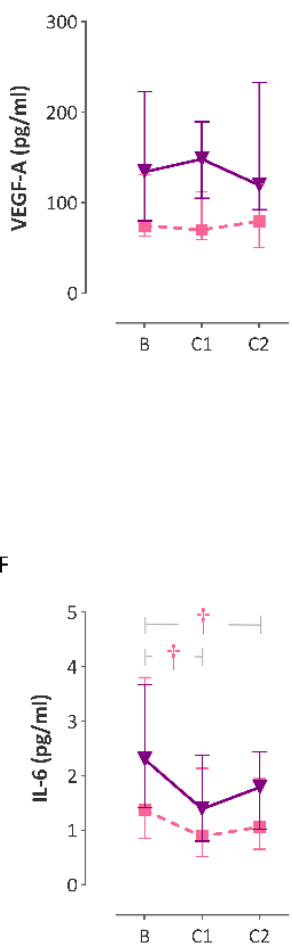
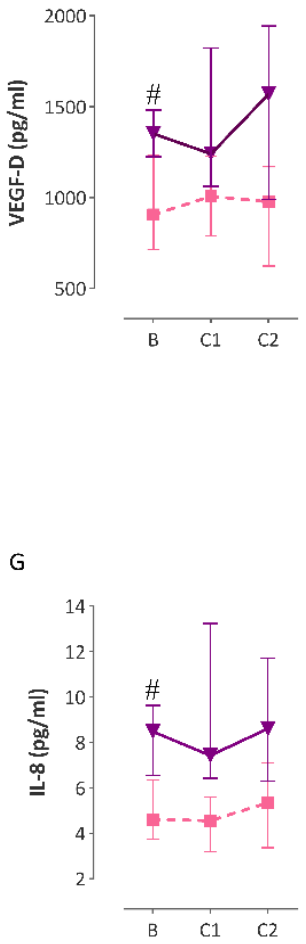

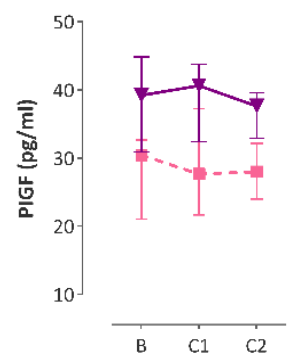

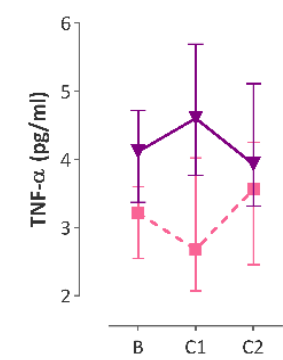

Patients are divided into IPAH/HPAH ( - - - ) and CTD-PAH ( - ) groups. $\ddagger$ indicates a significant change in the CTD-PAH group, during the marked period. $†$ indicates a significant change in the IPAH/HPAH group. \# marks significantly different baseline values between the CTD-PAH and IPAH/HPAH groups. B: Baseline; C1: First Checkup; C2: Second Checkup; CTD-PAH: Connective Tissue Disease Pulmonary Arterial Hypertension; FGF-2: Fibroblast Growth Factor 2; IL: Interleukin; IPAH: Idiopathic Pulmonary Arterial Hypertension; PIGF: Placental Growth Factor; sFlt-1: Soluble Fms-Like Tyrosine Kinase-1; Tie-2: Angiopoietin 1 Receptor; TNF- $\alpha$ : Tumor Necrosis Factor $\alpha$; VEGF: Vascular Endothelial Growth Factor.

Figure 4: Changes of selected biomarkers in PAH patients divided into in CTD-PAH and IPAH/HPAH subgroups.

Although the AMBITION trial has provided evidence for initial combination of endothelin receptor blockade with ambrisentan and phosphodiesterase 5 inhibition with tadalafil, further research is encouraged to evaluate the dynamics, efficacy and safety of other drug combinations. Different drugs have different molecular profiles, which may affect their interactions when combined with other drugs, as observed with different endothelin receptor antagonists. For instance, ambrisentan, unlike bosentan and macitentan, is selective for the Endothelin-A (ETA) receptor [25]. The ETA-receptors are expressed in vascular smooth muscle cells, whereas the Endothelin-B (ETB) receptors are expressed in endothelial and vascular smooth muscle cells [26]. Activation of ETA-receptors and ETB-receptors in vascular smooth muscle cells has vasoconstrictive and mitogenic effects, whereas activation of ETB-receptors in endothelial cells has vasodilating effects [26]. It could therefore be argued that selective inhibition of ETA-receptors may be better since it prevents vessel constriction and proliferation but preserves the vasodilating properties of the ETBreceptors. Recent analyses investigating pharmacokinetics of sildenafil and bosentan versus sildenafil and ambrisentan combinations showed that the latter combination had a higher area under the plasma concentration-time curve of sildenafil and a lower oral sildenafil clearance [27]. In relation to this, it is furthermore notable that the COMPASS-II trial (ClinicalTrials.gov identifier: NCT00303459), that evaluated sequential bosentan insertion on background sildenafil, did not meet its primary end-point, which was time to the first morbidity/ mortality event [28].
In pathology, however, ETB mediated vasodilation is suggested to be lost, while ETB-dependent vasoconstriction is suggested to be present [29]. In addition, macitentan administration, added on top of the maximal effective ambrisentan dose, has been shown to result in further systemic blood pressure reduction in hypertensive rats [29]. Macitentan was recently also shown to be beneficial for PAH patients with regards to the primary endpoint in the SERAPHIN trial (ClinicalTrials.gov identifier: NCT00660179) [30]. Notably, no clinically relevant pharmacokinetic interactions were observed between macitentan and sildenafil, in a pharmacokinetic investigation from Sidharta et al. [31] Taken together, although there is some evidence for the benefits of initial combination therapy, there are many routes yet to be investigated for optimal treatment approach with regards to which drugs that should be combined in PAH.

In addition to the fluctuations observed in plasma sFlt-1, in the present study, there was also a decrease in plasma IL-6 between baseline and the first checkup, which, nonetheless was reversed after the first checkup. IL-6 has previously been shown to be increased in blood samples from PAH patients and has been suggested to predict survival in these patients [4]. In PAH, IL-6 could be involved in signal transducer and activator of transcription 3 (STAT3)-mediated BMPR2 downregulation [5]. Also, transgenic mice that overexpress IL-6 exhibit pulmonary vascular and cardiac remodeling that is reminiscent to that seen in $\mathrm{PAH}$ [6]. Finally, we also noted increases in baseline plasma VEGF-D and IL-8 in CTD-PAH compared to IPAH/HPAH, which 
A. Changes $(\triangle)$ between baseline and first checkup

I

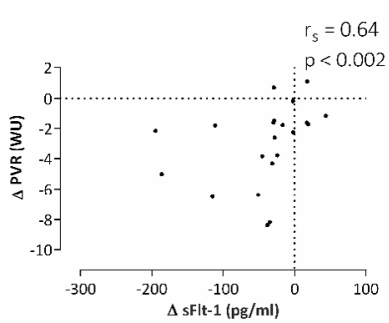

B . Changes $(\Delta)$ between baseline and second checkup

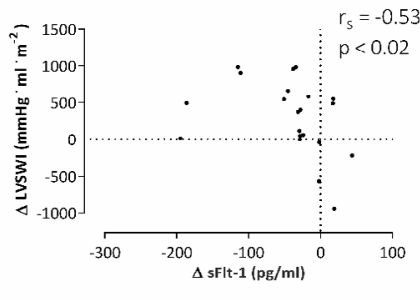

III

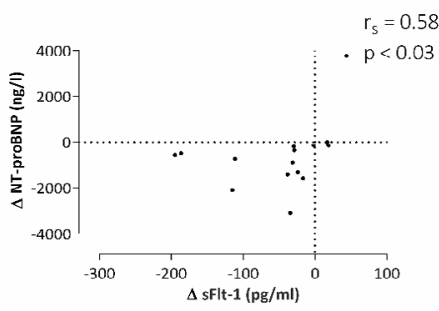

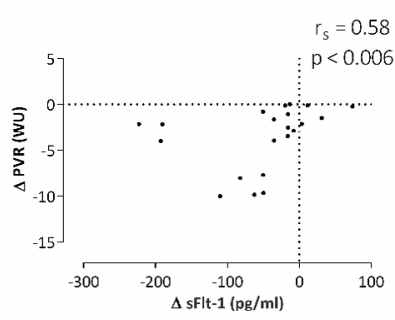

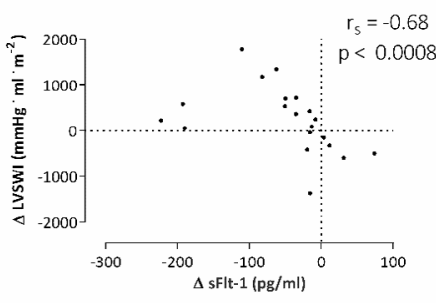

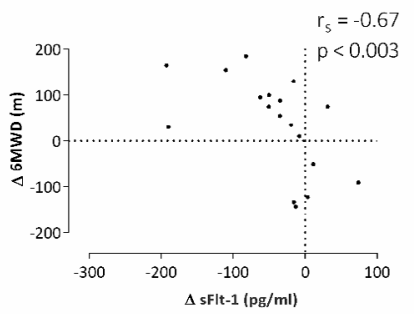

Parameter changes are observed either between (A) baseline and first checkup or (B) baseline and second checkup. 6MWD: 6-Minute Walk Distance; LVSWI: Left Ventricular Stroke Work; NT-proBNP: N-Terminal Prohormone of Brain Natriuretic Peptide; PVR: Pulmonary Vascular Resistance; sFlt-1: Soluble Fms-Like Tyrosine Kinase-1.

Figure 5: Correlations between changes of sFlt-1 and changes of clinical parameters.

may mirror the rheumatologic pathologies and the fact that these patients have a worse clinical course regarding $\mathrm{PAH}$.

The present study is subjected to some inherent limitations, related to the relatively small sample size. However, with the current study we aimed to investigate possible reflections of remodeling attenuation after a longer period with PAH therapy. To address this, we included patients with at least two RHC check-ups after baseline. Our stringent inclusion criteria resulted in a limited sample size. In addition, variations in baseline values, and probably remodeling, among patients in each group, may have affected the results. Nonetheless, this study may pave the way for larger future biomarker studies. Whether sFlt-1 is involved in the initiation and/or the progression of vascular remodeling in PAH remains elusive.

\section{Conclusion}

The present study suggests that plasma sFlt-1 is a potential biomarker of treatment response, in addition to its previously investigated diagnostic value. Fluctuations in sFlt-1 correlated with PVR and LVSWI changes, which allude to a potential pathological involvement for this protein. Initial combination therapy seems to result in a more potent initial depression in plasma sFlt-1 levels. Larger, collaborative studies are encouraged to further examine the use of plasma sFlt-1 as a treatment response biomarker in PAH.

\section{Acknowledgments}

We acknowledge the support of the staff at the Hemodynamic lab, The Section for Heart Failure and Valvular Disease, Skåne University Hospital and at the Department of Clinical Sciences Lund, Cardiology, Lund University, and Lund, Sweden as well as at the Centre for Inflammation and Metabolism, Rigshospitalet Copenhagen, Denmark.
The Centre for Physical Activity Research (CFAS) is supported by a grant from TrygFonden. During the study period, the Centre of Inflammation and Metabolism (CIM) was supported by a grant from the Danish National Research Foundation (DNRF55). CIM/CFAS is a member of DD2 - the Danish Center for Strategic Research in Type 2 Diabetes (the Danish Council for Strategic Research, grant no. 09-067009 and 09-075724).

\section{Conflicts of Interest}

Mr. Bouzina reports an unrestricted research grant from the Swedish Society of Pulmonary Hypertension on behalf of GlaxoSmithKline.

Dr. Rådegran reports unrestricted research grants from Actelion Pharmaceuticals Sweden $A B$ and GlaxoSmithKline, as well as personal lecture fees from Actelion Pharmaceuticals Sweden AB, GlaxoSmithKline, Bayer HealthCare $\mathrm{AB}$, Nordiclnfu Care and Sandoz/Novatris. Dr. Rådegran has been primary and/ or co-investigator for PAH trials for Actelion Pharmaceuticals AB, GlaxoSmithKline Pfizer, Bayer HealthCare AB and United Therapeutics.

\section{Funding}

The present work was supported by unrestricted research grants from the ALF foundation, Swedish Society of Pulmonary Hypertension, GlaxoSmithKline and Actelion Pharmaceuticals AB. The foundations had no role in the literature review selection, analysis and interpretation of the data or publication of the manuscript.

\section{References}

1. Galie N, Hoeper MM, Humbert M, Torbicki A, Vachiery JL, et al. (2009) Guidelines for the diagnosis and treatment of pulmonary hypertension: the Task Force for the Diagnosis and Treatment of Pulmonary Hypertension of the European Society of Cardiology (ESC) and the European Respiratory Society (ERS), endorsed by the International Society of Heart and Lung Transplantation (ISHLT). Eur Heart J 30: 2493-2537.

2. Galie N, Humbert M, Vachiery JL, Gibbs S, Lang I, et al. (2016) 2015 ESC/ ERS Guidelines for the diagnosis and treatment of pulmonary hypertension The Joint Task Force for the Diagnosis and Treatment of Pulmonary Hypertension of the European Society of Cardiology (ESC) and the European Respiratory Society (ERS): Endorsed by: Association for European Paediatric 
Citation: Bouzina H, Nielsen S, Scheele C, Rådegran G (2017) Plasma sFIt-1 Fluctuations in Response to Pulmonary Arterial Hypertension Treatment. Cardiovasc Pharm Open Access 6: 207. doi: 10.4172/2329-6607.1000207

and Congenital Cardiology (AEPC), International Society for Heart and Lung Transplantation (ISHLT). Eur Heart J 37: 67-119.

3. Tuder RM, Marecki JC, Richter A, Fijalkowska I, Flores S (2007) Pathology of Pulmonary Hypertension. Clin Chest Med 28: 23.

4. Soon E, Holmes AM, Treacy CM, Doughty NJ, Southgate L, et al. (2010) Elevated levels of inflammatory cytokines predict survival in idiopathic and familial pulmonary arterial hypertension. Circulation 122: 920-927.

5. Brock M, Trenkmann M, Gay RE, Michel BA, Gay S, et al. (2009) Interleukin-6 modulates the expression of the bone morphogenic protein receptor type II through a novel STAT3-microRNA cluster $17 / 92$ pathway. Circ Res 104: 11841191.

6. Steiner MK, Syrkina OL, Kolliputi N, Mark EJ, Hales CA, et al. (2009) Interleukin-6 overexpression induces pulmonary hypertension. Circ Res 104 236-244.

7. Benisty JI, McLaughlin VV, Landzberg MJ, Rich JD, Newburger JW, et al. (2004) Elevated basic fibroblast growth factor levels in patients with pulmonary arterial hypertension. Chest 126: 1255-1261.

8. Izikki M, Guignabert C, Fadel E, Humbert M, Tu L, et al. (2009) Endothelialderived FGF2 contributes to the progression of pulmonary hypertension in humans and rodents. J Clin Invest 119: 512-523.

9. Taraseviciene SL, Kasahara Y, Alger L, Hirth P, Mc Mahon G, et al. (2001) Inhibition of the VEGF receptor 2 combined with chronic hypoxia causes cell death-dependent pulmonary endothelial cell proliferation and severe pulmonary hypertension. FASEB 15: 427-438.

10. Campbell Al, Zhao Y, Sandhu R, Stewart DJ (2001) Cell-based gene transfer of vascular endothelial growth factor attenuates monocrotaline-induced pulmonary hypertension. Circulation 104: 2242-2248.

11. Partovian C, Adnot S, Raffestin B, Louzier V, Levame M, et al. (2000) Adenovirus-mediated lung vascular endothelial growth factor overexpression protects against hypoxic pulmonary hypertension in rats. Am J Resp Cell Mol Biol 23: 762-771.

12. Kumpers P, Nickel N, Lukasz A, Golpon H, Westerkamp V, et al. (2010) Circulating angiopoietins in idiopathic pulmonary arterial hypertension. Eur Heart J 31: 2291-2300.

13. Selimovic N, Bergh CH, Andersson B, Sakiniene E, Carlsten H, et al. (2009) Growth factors and interleukin-6 across the lung circulation in pulmonary hypertension. Eur Resp J 34: 662-668.

14. Wu FT, Stefanini MO, Mac Gabhann F, Kontos CD, Annex BH, et al. (2010) A systems biology perspective on SVEGFR1: its biological function, pathogenic role and therapeutic use. J Cell Mol Med 14: 528-552.

15. Malhotra R, Paskin FS, Zamanian RT, Zimmerman P, Schmidt JW, et al. (2013) Circulating angiogenic modulatory factors predict survival and functional class in pulmonary arterial hypertension. Pulm Circul 3: 369-380.

16. Tiede SL, Gall H, Dorr O, Troidl C, Liebetrau C, et al. (2015) New potential diagnostic biomarkers for pulmonary hypertension. Eur Res J 46: 1390-1396.

17. Di Marco GS, Reuter S, Hillebrand U, Amler S, Konig M, et al. (2009) The soluble VEGF receptor sFlt1 contributes to endothelial dysfunction in CKD. J Am Soc Nephrol 20: 2235-2245.
18. Maynard SE, Min JY, Merchan J, Lim KH, Li J, et al. (2003) Excess placental soluble fms-like tyrosine kinase 1 (sFlt1) may contribute to endothelial dysfunction, hypertension, and proteinuria in preeclampsia. J Clin Invest 111 649-658.

19. Amraoui F, Spijkers L, Hassani LH, Vogt L, Van der Post J, et al. (2014) SFlt-1 elevates blood pressure by augmenting endothelin-1-mediated vasoconstriction in mice. PloS One 9: e91897.

20. Voelkel NF, Gomez AJ (2014) The role of vascular endothelial growth factor in pulmonary arterial hypertension. The angiogenesis paradox. Am J Resp Cell Mol Biol 51: 474-484

21. Janvier A, Nadeau S, Baribeau J, Perreault T (2005) Role of vascular endothelia growth factor receptor 1 and vascular endothelial growth factor receptor 2 in the vasodilator response to vascular endothelial growth factor in the neonatal piglet lung. Crit Care Med 33: 860-866.

22. Fernandez AR, Husain R (2015) Vascular endothelial growth factor, soluble fms-like tyrosine kinase 1 and genistein-induced changes in the vascular reactivity of rat's aorta. J Obstetr Gynaecol Res 41: 277-282.

23. Galiè N, Barberà JA, Frost AE, Ghofrani HA, Hoeper MM, et al. (2015) Initial Use of Ambrisentan plus Tadalafil in Pulmonary Arterial Hypertension. NEJM 373: 834-844.

24. Kylhammar D, Persson L, Hesselstrand R, Radegran G (2014) Prognosis and response to first-line single and combination therapy in pulmonary arterial hypertension. Scand Cardiovasc J 48: 223-233.

25. Vatter H, Seifert V (2006) Ambrisentan, a non-peptide endothelin receptor antagonist. Cardiovas Drug Rev 24: 63-76.

26. Galie N, Manes A, Branzi A (2004) The endothelin system in pulmonary arterial hypertension. Cardiovas Res 61: 227-237.

27. Hakamata A, Odagiri K, Miyakawa S, Irisawa H, Takeuchi K, et al. (2016) Pharmacokinetic and Pharmacodynamic Comparison of SildenafilBosentan and Sildenafil-Ambrisentan Combination Therapies for Pulmonary Hypertension. Clin Translation Sci.

28. McLaughlin V, Channick RN, Ghofrani HA, Lemarie JC, Naeije R, et al. (2015) Bosentan added to sildenafil therapy in patients with pulmonary arteria hypertension. Eur Resp J 46: 405-413.

29. Iglarz M, Steiner P, Wanner D, Rey M, Hess $P$, et al. (2015) Vascular Effects of Endothelin Receptor Antagonists Depends on Their Selectivity for ETA Versus ETB Receptors and on the Functionality of Endothelial ETB Receptors. J Cardiovasc Pharmacol 66: 332-337.

30. Pulido T, Adzerikho I, Channick RN, Delcroix M, Galiè N, et al. (2013) Macitentan and Morbidity and Mortality in Pulmonary Arterial Hypertension. NEJM 369: 809-818.

31. Sidharta PN, Van Giersbergen PL, Wolzt M, Dingemanse J (2014) Investigation of mutual pharmacokinetic interactions between macitentan, a novel endothelin receptor antagonist, and sildenafil in healthy subjects. Br J Clin Pharmacol 78 1035-1042. 


\begin{tabular}{|c|c|c|c|c|c|c|}
\hline & & All patients & CTD-PAH & IPAH/HPAH & Initial combination therapy & Initial monotherapy \\
\hline Sample size (\% females) & & $21(71)$ & $8(100)$ & $13(54)$ & $5(80)$ & $16(69)$ \\
\hline Age (years) & & $70(57-75)$ & $70(62-73)$ & $72(57-75)$ & $55(45-70)$ & $72(66-77)$ \\
\hline $\mathrm{BSA}\left(\mathrm{m}^{2}\right)$ & & $1.78(1.7-2.08)$ & $1.72(1.69-1.77)$ & $1.89(1.77-2.17)$ & $1.78(1.66-2.08)$ & $1.78(1.7-2.05)$ \\
\hline MPAP (mmHg) & B & $45(39-55)$ & $41.5(38.8-44.3)$ & $50(42-55)$ & $56(50-57)$ & $43.5(38.8-49.8)$ \\
\hline MPAP (mmHg) & $\mathrm{C} 1$ & $40(34-48)$ & $36(33.5-42)$ & $41(35-48)$ & $48(42-48)$ & $39(34-42.8)$ \\
\hline $\operatorname{MPAP}(\mathrm{mmHg})$ & C2 & $39(34-44) \ddagger$ & $39(35.5-43)$ & $37(30-44) \ddagger$ & $39(39-41)$ & $36.5(30-44.5) \neq$ \\
\hline PAWP (mmHg) & B & $6(5-7)$ & $6(5-6.3)$ & $6(5-7)$ & $6(6-7)$ & $6(5-6.3)$ \\
\hline PAWP (mmHg) & $\mathrm{C} 1$ & $6(5-10)$ & $5.5(4.8-9)$ & $6(5-10)$ & $6(5-7)$ & $6(4.8-10)$ \\
\hline PAWP (mmHg) & C2 & $6(5-9)$ & $7(6-8.3)$ & $5(5-9)$ & $5(5-6)$ & $7(5-9.3)$ \\
\hline MRAP (mmHg) & B & $7(6-9)$ & $7(6-10)$ & $7(4-9)$ & $9(7-11)$ & $6(4-8.3)$ \\
\hline MRAP (mmHg) & $\mathrm{C} 1$ & $6(4-10)$ & $8.5(5.8-11)$ & $4(3-8)$ & $6(6-11)$ & $6(3.8-9.3)$ \\
\hline MRAP (mmHg) & C2 & $4(4-8)$ & $11(6.3-15)$ & $4(2-6) \neq$ & $4(4-8)$ & $5(3.5-8.5)$ \\
\hline $\mathrm{CO}\left(1 \cdot \mathrm{min}^{-1}\right)$ & B & $3.6(3-4.6)$ & $3.6(3.1-4.7)$ & $3.6(3-4.4)$ & $3(2.9-3)$ & $3.9(3.4-4.9) *$ \\
\hline $\operatorname{CO}\left(1 \cdot \mathrm{min}^{-1}\right)$ & $\mathrm{C} 1$ & $4.5(3.5-5.7) \ddagger$ & $4.7(3.5-5.2) 末$ & $4.5(3.5-5.7) \neq$ & $3.6(3.5-5)$ & $4.7(3.6-5.8) \ddagger$ \\
\hline $\mathrm{CO}\left(1 \cdot \mathrm{min}^{-1}\right)$ & $\mathrm{C} 2$ & $4.2(3.5-4.9) \ddagger$ & $3.8(3.3-4.5)$ & $4.8(3.7-5.9) \neq$ & $3.8(3.5-3.8) \neq$ & $4.6(3.7-5.1)$ \\
\hline PVR (WU) & B & $10.2(7.9-12.4)$ & $8.9(7.2-11)$ & $11.9(8.2-14.5)$ & $16.9(14.9-17.2)$ & $8.8(7.3-11.3)^{*}$ \\
\hline PVR (WU) & $\mathrm{C} 1$ & $7.5(5.8-9.3) *$ & $7.3(5.7-8.9) \ddagger$ & $7.5(6.5-9.6) \ddagger$ & $10.4(6.5-12.2)$ & $7.1(5.8-8.8) \neq$ \\
\hline PVR (WU) & C2 & $7.8(6-8.9) \ddagger$ & $8.3(6-8.9)$ & $6.9(6.3-8.9) \ddagger$ & $8.9(8.7-9.1) \ddagger$ & $6.7(6-8.7) \neq$ \\
\hline SVR (WU) & B & $25.4(18.3-28.3)$ & $23.1(17.7-25.9)$ & $26(19.8-32.4)$ & $26.7(26-32.4)$ & $23.6(17.2-27.1)$ \\
\hline SVR (WU) & $\mathrm{C} 1$ & $16.9(13-24.8) \ddagger$ & $16.8(12.7-19.8) \div$ & $18.9(13.8-25.7) \ddagger$ & $19.2(13-25.7) \neq$ & $16.8(13.6-22.3) \ddagger$ \\
\hline SVR (WU) & C2 & $16.3(14.7-21.4) \neq$ & $19.6(15.3-22.1)$ & $16(14.7-20) \neq$ & $21.6(14.7-24.9)$ & $16.2(15.3-20.2) \neq$ \\
\hline $\mathrm{RVSWI}\left(\mathrm{mmHg} \cdot \mathrm{ml} \cdot \mathrm{m}^{-2}\right)$ & B & $921.7(800.6-1137.7)$ & $853.9(799.2$ - 975.7) & $1001.6(800.6-1211.2)$ & $800.6(776.8-898.9)$ & $1005.9(808.4-1230.5)$ \\
\hline RVSWI (mmHg.ml. $\left.\mathrm{m}^{-2}\right)$ & $\mathrm{C} 1$ & $1065.4(961.4-1330.8)$ & $977.3(849.4-1349.4)$ & $1083.6(962.8-1305.4)$ & 978.5 (976 - 1058.6) & $1169.6(861.8-1365.2)$ \\
\hline $\mathrm{RVSWI}\left(\mathrm{mmHg} \cdot \mathrm{ml} \cdot \mathrm{m}^{-2}\right)$ & $\mathrm{C} 2$ & $995.2(693.9-1254.6)$ & $729.3(597.7-1026.8)$ & $1203.3(920-1288.5)$ & $1203.3(963.6-1206.7)$ & $957.6(597.7-1370.2)$ \\
\hline LVSWI (mmHg.ml.m $\left.{ }^{-2}\right)$ & B & $2159.4(1969.7-2600.7)$ & $2133.1(1919.7-2755)$ & $2175.7(1969.7-2600.7)$ & $1635.3(1598.5-1863)$ & $2429.3(2114-2938.8) *$ \\
\hline LVSWI (mmHg $\left.\cdot \mathrm{ml} \cdot \mathrm{m}^{-2}\right)$ & $\mathrm{C} 1$ & $2581.2(2155.7-2835.6)$ & $2529.3(2068.8-2716.8)$ & $2617.2(2407.7-2858.3)$ & $2477.5(2407.7-2556.5)$ & 2665 (2139.4 - 2918.6) \\
\hline LVSWI (mmHg $\left.\cdot \mathrm{ml} \cdot \mathrm{m}^{-2}\right)$ & C2 & $2548.4(2104.7-3122.7) \ddagger$ & $2107(2085.6-2940.1)$ & $2573.5(2231.2-3155.3)$ & $2573.5(2104.7-2819.2)$ & $2475.4(2104.6-3130.9)$ \\
\hline
\end{tabular}

Continuous variables are presented as median (interquartile range). Baseline values significantly different between initial combination versus monotherapy groups are marked by a *. $¥$ notes a significant difference between the marked value and the baseline value for the addressed parameter and group. B, baseline; $\mathrm{C}$, first checkup; C2, second checkup; CTD-PAH, connective tissue disease pulmonary arterial hypertension; HPAH, hereditary pulmonary arterial hypertension; IPAH, idiopathic pulmonary arterial hypertension; MPAP, mean pulmonary arterial pressure; MRAP, mean right atrial pressure; PAWP, pulmonary artery wedge pressure; PVR, pulmonary vascular resistance; RVSWI, right ventricular stroke work index; SVR, systemic vascular resistance; WU, wood unit.

Supplementary table 1B. WHO-FC, 6MWD and NT-proBNP values for PAH patients.

\begin{tabular}{|c|c|c|c|c|c|c|}
\hline & & All patients & CTD-PAH & $\mathrm{IPAH} / \mathrm{HPAH}$ & Initial combination therapy & Initial monotherapy \\
\hline Sample size (\% females) & & $21(71)$ & $8(100)$ & $13(54)$ & $5(80)$ & $16(69)$ \\
\hline WHO-FC & B & $3(3-3)$ & $3(3-3)$ & $3(3-3)$ & $3(3-3)$ & $3(3-3)$ \\
\hline WHO-FC & $\mathrm{C} 1$ & $3(2-3)$ & $3(3-3)$ & $3(2-3)$ & $2(2-3)$ & $3(3-3)$ \\
\hline WHO-FC & $\mathrm{C} 2$ & $3(3-3)$ & $3(3-3)$ & $3(2-3)$ & $3(2-3)$ & $3(3-3)$ \\
\hline $6 \mathrm{MWD}(\mathrm{m})$ & B & $213.5(142.5-258.5)$ & $207(157.5-251)$ & $220(162.5-260)$ & $241.5(213.8-278.5)$ & $203.5(121.3-243.5)$ \\
\hline 6MWD $(\mathrm{m})$ & $\mathrm{C} 1$ & $240(168.5-310)$ & $187(151-263)$ & $255(200-345)$ & $302(274.5-344.8)$ & $208.5(143.3-270)$ \\
\hline $6 \mathrm{MWD}(\mathrm{m})$ & $\mathrm{C} 2$ & $224(150-371.3) \ddagger$ & $150(123-200.5)$ & $275(175-375) \ddagger$ & $367.5(302.5-408.8)$ & $176.5(150-273.8)$ \\
\hline NT-proBNP (ng/l) & B & $2359(1666.5-3088.5)$ & $3259.5(2603.8-4089.3)$ & $1689(843-2359) \dagger$ & $2634.5(2338.8-2977.8)$ & $2325(1243.5-3088.5)$ \\
\hline NT-proBNP (ng/l) & $\mathrm{C} 1$ & $1455(642-2468.5) \neq$ & $2468.5(1658.8-3532.5)$ & $707(391$ - 1054) & $1133.5(674.5-1915.5)$ & $1455(619-2835.5)$ \\
\hline NT-proBNP (ng/l) & $\mathrm{C} 2$ & $958(420.5-3264.5) \ddagger$ & $3264.5(2597.8-5147)$ & $541(140-958) \ddagger$ & $2104.5(753.5-3257.8)$ & $700(420.5-3012.5)$ \\
\hline
\end{tabular}

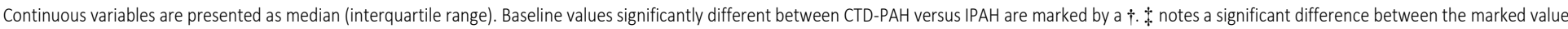

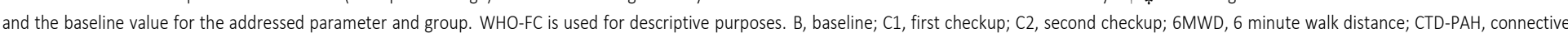

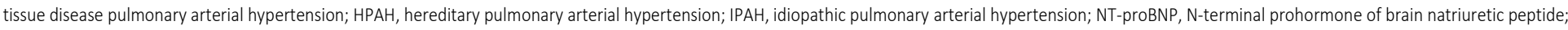
WHO-FC, World Health Organization functional class. 
Supplementary table 1C. Biomarker values for PAH patients.

\begin{tabular}{|c|c|c|c|c|c|c|}
\hline & & All patients & CTD-PAH & IPAH/HPAH & Initial combination therapy & Initial monotherapy \\
\hline Sample size (\% females) & & $21(71)$ & $8(100)$ & $13(54)$ & $5(80)$ & $16(69)$ \\
\hline $\mathrm{FGF}-2(\mathrm{pg} / \mathrm{ml})$ & B & $15.16(10.75-20.64)$ & $14.02(9.99-14.43)$ & $17.89(13.49-26.11)$ & $17.47(14.18-18.65)$ & $14.66(10.1-23.48)$ \\
\hline FGF-2 (pg/ml) & C1 & 14.37 (7.19 - 29.09) & $8.99(7.77-17.45)$ & $24.3(7.19-41.17)$ & $16.87(7.99-28.38)$ & $12.09(7.17-31.53)$ \\
\hline FGF-2 (pg/ml) & $\mathrm{C} 2$ & $15.75(7.53-21.92)$ & $17.81(13.41-20.58)$ & $14.1(7.23-43.07)$ & $5.84(5.05-7.53)$ & $17.81(13.18-43.74)$ \\
\hline PIGF (pg/ml) & B & $31.02(21.74-38.14)$ & $39.22(30.93-44.85)$ & $30.44(21.07-32.68)$ & $30.66(18.09-32.68)$ & $31.45(26.86-39.58)$ \\
\hline PIGF (pg/ml) & $\mathrm{C} 1$ & $34.64(26.38-40.94)$ & $40.61(32.41-43.72)$ & $27.65(21.67-37.2)$ & $27.65(20.06-28.33)$ & $35.94(26.51-42.72)$ \\
\hline PIGF (pg/ml) & $\mathrm{C} 2$ & $30.96(26.52-36.8)$ & $37.62(32.9-39.62)$ & $28(24.01-32.14)$ & $28.56(26.52-39.48)$ & $31.55(27.32-36.49)$ \\
\hline sFlt-1 (pg/ml) & B & $124(95.2-148.9)$ & $125.9(92-330.5)$ & $124(103.6-144.2)$ & $188(130.6-214.1)$ & $119.3(89.2-138.7)$ \\
\hline sFlt-1 (pg/ml) & $\mathrm{C} 1$ & $110.2(79.9-127.7)$ * & $103(73.8-145) \neq$ & $110.2(99-127.3)$ & $99(79.9-141.4) \neq$ & $112.2(84-127.4)$ \\
\hline sFlt-1 (pg/ml) & $\mathrm{C} 2$ & $93.7(79.2-116)$ \$ & $108.8(82.1-141.4)$ & $88.5(78.2-104.4) \ddagger$ & $80.6(79.2-132)$ & $94.5(81.8-115) \ddagger$ \\
\hline Tie-2 (pg/ml) & B & $3284.8(2818.9-3607.4)$ & $2832.5(2741.4-3168.7)$ & $3415.9(2984-3769.6)$ & $3284.8(3110.3-3415.9)$ & $3163.9(2813.1-3695.7)$ \\
\hline Tie-2 (pg/ml) & $\mathrm{C} 1$ & $3118.3(2727.3-3427.9)$ & $2787.4(2543.8-3103.6)$ & $3234.5(3102-3450.9)$ & $3222.1(2694.3-3415.7)$ & $3110.1(2764.8-3449.6)$ \\
\hline Tie-2 (pg/ml) & $\mathrm{C} 2$ & $3436.2(2983.5-3676.4)$ & $3076.5(2657.8-3303.3)$ & $3641.5(3092.7-3850.4)$ & $3502.6(2889.3-3621.1)$ & 3347.6 (3036.9 - 3718.7) \\
\hline VEGF-A (pg/ml) & B & $81(73.6-150.4)$ & $133.9(79.8-222.5)$ & $74.4(62.5-131.2)$ & $74.3(73.6-79.9)$ & $122.7(72.7-155.1)$ \\
\hline VEGF-A (pg/ml) & $\mathrm{C} 1$ & $96.6(69.4-170.3)$ & $148(104.8-189.3)$ & $69.8(59.3-112)$ & $112(53.5-151.2)$ & $94.2(69.7-189.3)$ \\
\hline VEGF-A (pg/ml) & $\mathrm{C} 2$ & $92.8(59.9-176.2)$ & $119.3(92.4-233.1)$ & $79.5(50.4-120.9)$ & $79.5(40.8-92.8)$ & $109(68.6-176.5)$ \\
\hline VEGF-D (pg/ml) & B & $1222.8(801.5-1322.7)$ & $1351.7(1224.8-1482)$ & $905.8(712.5-1230.5) \dagger$ & $1222.8(690.3-1232.4)$ & $1216.3(853.2-1357.8)$ \\
\hline VEGF-D (pg/ml) & $\mathrm{C} 1$ & $1098.8(821.5-1324.6)$ & $1239.9(1060.6-1824.8)$ & $1007.1(789.1-1227.4)$ & $969.7(835-1007.1)$ & $1215.1(814.8-1363.5)$ \\
\hline VEGF-D (pg/ml) & C2 & $1060.5(722.1$ - 1437.1) & $1569.2(989.4$ - 1943.8) & $976.8(624.6-1169.2)$ & $1036.3(722.1$ - 1161.7) & $1114.9(782.2-1466.6)$ \\
\hline IL-6 (pg/ml) & B & $1.58(0.9-3.8)$ & $2.3(1.42-3.67)$ & $1.37(0.86-3.8)$ & $1.47(0.9-1.85)$ & $1.69(1-3.84)$ \\
\hline IL-6 (pg/ml) & $\mathrm{C} 1$ & $1.3(0.57-2.33) \neq$ & $1.39(0.8-2.37)$ & $0.88(0.52-2.14) \ddagger$ & $0.73(0.57-1.31)$ & $1.34(0.66-2.33) \ddagger$ \\
\hline IL-6 (pg/ml) & $\mathrm{C} 2$ & $1.56(0.74-2.01)$ & $1.79(1.01-2.44)$ & $1.06(0.65-1.94) \ddagger$ & $0.94(0.65-1.06)$ & $1.94(0.86-2.18)$ \\
\hline IL-8 (pg/ml) & B & $5.35(3.84-7.96)$ & $8.48(6.54-9.62)$ & $4.6(3.74-6.34) \dagger$ & $6.34(4.6-6.94)$ & $5.24(3.73-8.22)$ \\
\hline IL-8 (pg/ml) & $\mathrm{C} 1$ & $5.6(4.1-8)$ & $7.43(6.43-13.23)$ & $4.56(3.18-5.6)$ & $5.09(4.1-6.58)$ & $5.79(4.3-8.16)$ \\
\hline IL-8 (pg/ml) & $\mathrm{C} 2$ & $6.32(4.31-8.65)$ & $8.61(6.29-11.7)$ & $5.35(3.38-7.12)$ & $6.47(6.08-7.74)$ & $6.26(4.15-8.86)$ \\
\hline TNF- $\alpha(\mathrm{pg} / \mathrm{ml})$ & B & $3.39(2.79-4.28)$ & $4.12(3.37-4.72)$ & $3.21(2.55-3.6)$ & 2.55 (2.47 - 3.39) & $3.5(3.2-4.33)$ \\
\hline TNF- $\alpha(\mathrm{pg} / \mathrm{ml})$ & $\mathrm{C} 1$ & $3.62(2.45-4.79)$ & $4.6(3.77-5.69)$ & $2.68(2.07-4.02)$ & $2.68(2.35-4.41)$ & $3.74(2.82-4.84)$ \\
\hline TNF- $\alpha(p g / m l)$ & $\mathrm{C} 2$ & $3.59(2.74-4.8)$ & $3.93(3.31-5.11)$ & $3.56(2.46-4.25)$ & $3.68(3.28-4.05) \$$ & $3.58(2.37-4.87)$ \\
\hline
\end{tabular}

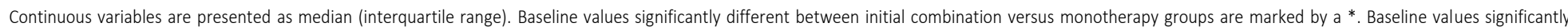

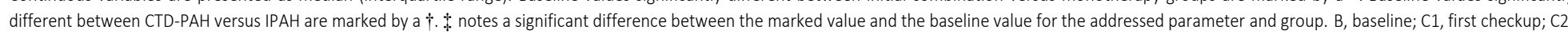

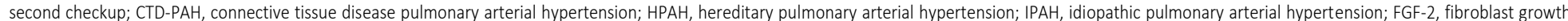

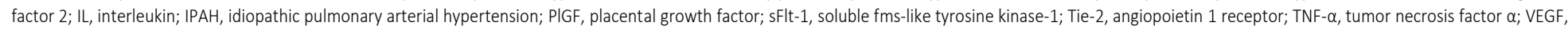
vascular endothelial growth factor. 